\title{
VORWORT DES UBERSETZERS
}

Die vorliegende deutsche Ausgabe von Stephen Ullmanns Principles of Semantics folgt der zweiten Auflage, die gegenüber der von 1951 um einen 1957 nachgetragenen Forschungsbericht über neuere Strömungen in der Semantik sowie um zwei bibliographische Nachträge von 1959 und 1963 vermehrt ist. Letztere haben wir, um dem Leser die Benutzung zu erleichtern, in das allgemeine Literaturverzeichnis eingearbeitet, zumal dieses von Ullmann bereits für die zweite Auflage auf Neuerscheinungen ausgedehnt worden war, die in den Grundzügen selbst noch nicht berücksichtigt sind, die die Bibliographie gleichwohl kompendienartig weiterführen. Der auf ein bloßes Sachregister beschränkte Index des Originals ist für die deutsche Ausgabe um ein Personenregister und um ein Wortregister vermehrt worden. Erst so erschließt sich die ganze Fülle des verarbeiteten Materials auch für den, der die Grundzüge nur als Handbuch benutzen möchte. Zugleich wird so mit einem Blick deutlich, auf welch große, hierzulande zuweilen aber auch unbekannt gebliebene Namen der Verfasser sein System einer vorwiegend deskriptiven Semantik stützt.

Angesichts der Tatsache, daß in den Grundzügen überaus viele Schriften zur Bedeutungslehre aus den letzten fünfzig Jahren vorgestellt und verarbeitet sind, schien es geboten, die so reichlich zitierte Literatur nach Möglichkeit noch einmal bibliographisch zu überprüfen. Die Angaben als solche werden davon natürlich nicht berührt; wohl aber haben sich gegenüber dem Original zahlreiche Korrekturen ergeben, die der Verfasser vermutlich auch selbst schon angebracht hätte, wäre er in allen weiteren Auflagen nicht an den photomechanischen Nachdruck gebunden gewesen. Zudem ist nach Möglichkeit auf leichter zugängliche Ausgaben, neuere Auflagen, inzwischen erschienene Aufsatzsammlungen etc. umpaginiert; waren die vom Autor benutzten Auflagen nicht greifbar, wird gelegentlich allerdings auch nach älteren zitiert. Um den Anmerkungsteil für den Leser noch leichter zugänglich zu machen, haben wir viele nichtssagende oder gar irreführende "op. cit.“ bzw. "loc. cit." der Vorlage durch Kurztitel spezifiziert; wo die näheren Angaben dagegen eindeutig aus dem Literaturverzeichnis hervorgehen, nennen wir nur Verfasser und Seitenzahlen. Gelegentliche zusätzliche Literaturangaben, die zur Erklärung eines im Englischen selbstverständlichen Sachverhalts gedacht sind, erscheinen in eckigen Klammern.

Die Ubersetzung selbst ist um eine durchsichtige Begriffsbildung bemüht; in einigen Fällen sind die Ullmannschen Termini zur Kontrolle beigefügt. Englische Beispiele sind durch deutsche Entsprechungen erweitert bzw. ersetzt; 
wo das nicht möglich war, folgt in Klammern die Übersetzung. Diese fehlt jedoch, wenn Wörter aus mehreren Sprachen zu Beispielreihen zusammengesetzt sind. Zitate aus fremdsprachiger Fachliteratur sind grundsätzlich nicht mitübersetzt, da sie nicht in die Terminologie und Diktion der Grundzüge eingefärbt werden sollten. Sie sind vielmehr in jedem Fall, auch wo es sich um englisch paraphrasierte Zitate aus holländischer oder deutschsprachiger Literatur handelt, nach dem Original zitiert. Soweit dafür Ubersetzungen vorliegen, haben wir diese selbstverständlich benutzt. Nur für Saussure sind jeweils auch die Seitenzahlen der französischen Ausgabe mitverzeichnet, um das Auffinden der für Ullmann grundlegenden, von ihm vielzitierten Originalformulierungen zu erleichtern. Als Beispiele angeführte dichterische Wendungen und literarische Zitate haben wir generell weder übersetzt noch nach Ubersetzungen zitiert, da sonst die Nuancen, auf die es dabei ankommt, erfahrungsgemäß verlorengehen. Es schien darum wichtiger und richtiger, den genauen Wortlaut solcher Stellen zu sichern, was bedeutet, daß für die deutsche Ausgabe viele Belege nachgetragen und indirekte Quellen durch direkte ersetzt worden sind. Derartige Stellennachweise erscheinen als Ergänzungen des Ubersetzers in eckigen Klammern.

Bei all diesen Bemühungen hat der Obersetzer beileibe nicht klüger sein wollen als sein Autor; da es bei der Obersetzung einer Semantik mehr denn je auf jedes Wort ankommt, hat er sich seiner Vorlage im Gegenteil besonders verpflichtet gefühlt. Natürlich stellt sich damit erst recht das Dilemma ein, das wir dem Leser in der treffenden Formulierung Carl Bertrands doch auch zu bedenken geben wollen: „Ubersetzungen gleichen den Frauen: sind sie treu, so sind sie nicht schön, und sind sie schön, so sind sie nicht treu!“ 